\title{
EL DESARROLLO HUMANO Y EL CONOCIMIENTO O LA METÁFORA DE LAS MANZANAS: LA MANZANA DE EVA A LA "APPLE" DE BILL GATES
}

\section{THE HUMAN DEVELOPMENT AND KNOWLEDGE OR THE METAPHOR OF APPLES: FROM EVA'S APPLE TO BILL GATES "APPLE"}

\author{
Rui Proença Garcia: ${ }^{1}$ Universidad do Porto (Portugal) \\ franciscoproencagarcia@iep.lisboa.ucp.pt
}

\section{RESUMEN}

Esta disertación es de tipo antropológica y a la vez filosófica donde se reflexiona sobre el desarrollo humano en cuanto a la concepción del conocimiento (gnoseología) y la visión del alcance de lo real haciendo un recorrido retrospectivohistórico a través de la sugerente metáfora de la manzana por protagonistas de la Historia en momentos memorables (la manzana de Eva, de Newton, de Bill Gates, etc). Más que contestar preguntas este escrito realiza sugerentes preguntas a partir de planteamientos filosóficos o reflexiones sobre los sucesos históricos. Este escrito hace reflexionar desde un punto de vista ético sobre la actual epistemología vista por la autoridad que otorgamos a lo científico y a lo tecnológico mientras lo real se sigue mostrando hasta un punto misterioso y donde el hombre todavía se está descubriendo a sí mismo. No cabe duda que este debe respetarse y ser fiel a sí mismo, a su dignidad.

\section{PALABRAS CLAVE: desarrollo humano- epistemología - ética - sociedad- dignidad humana.}

\section{ABSTRACT}

This dissertation is based on anthropological and philosophical point of view where we reflect on human development in terms of the conception of knowledge (epistemology) and the vision of the real travelling a retrospective-historical journey through the suggestive metaphor of the apple by protagonists of history in memorable moments (Eve's apple, Newton, Bill Gates, etc). This writting opens more questions than answers. It makes suggestive questions from philosophical approaches or reflections on historical events. This thought-provoking writing from an ethical point of view on the current epistemology authority's approaches the strength of scientific and technological to understand reality and conceive humans on society. This text still displays that humans and reality are mysterious and man must still have

${ }^{1}$ Rui Proença Garcia: Posee doctorado en Doctorado en Ciencias del Deporte por la Universidad de Oporto (1994). Actualmente es profesor titular de la Universidad de Oporto 
to discover himself. No doubt that man in any approach or time must be respected and be true to himself, to his dignity.

\section{KEY WORDS: ethics - society- human dignity-epistemology- human development.}

Cómo citar el artículo:

Rui Proença Garcia. (2013) EL DESARROLLO HUMANO Y EL
CONOCIMIENTO O LA METÁFORA DE LAS MANZANAS: LA MANZANA DE
EVA A LA "APPLE" DE BILL GATES. Revista de Ciencias de la Comunicación e
Información. (Diciembre 2013). Año XXVII (30), 25-36 ISSN: 0213-070-X. Recuperado
de: http://www.revistaccinformacion.net/ARTICULOS/2013\%20e-j\%20Bea/2013\%20e-
\%20EI\%20desarrollo\%20humano\%20y\%20el\%20conocimiento..\%20Rui\%20Proen\%C3
\%A7a.pdf

\section{INTRODUCCIÓN}

Esta dissertação é antropológica e, ao mesmo tempo, filosófica. Reflete sobre o desenvolvimento humano ao longo dos séculos em termos da concepção de conhecimento (gnoseologia), a visão do alcance do real e a concepção de homem que se tornou uma jornada retrospectiva-histórica a sugestiva metáfora da maçã pelos protagonistas da História em três momentos memoráveis (a era bíblica, a era racional e a era tecnológica).

Este artigo faz perguntas sugestivas a partir de abordagens filosóficas ou reflexões sobre eventos históricos para indicar até que ponto é importante que o homem considere em todos os momentos como sua visão da realidade tem consequências éticas que devem ser revistas. Esta escrita reflete de um ponto de vista ético sobre a epistemologia atual vista pela autoridade que damos ao científico e tecnológico, enquanto o real ainda está se mostrando em um ponto misterioso e onde o homem ainda está se descobrindo. Não há dúvida de que isso deve ser respeitado e ser fiel a si mesmo, à sua dignidade.

\section{OBJETIVOS}

O objetivo desta dissertação é propor uma crítica da epistemologia atual e da situação atual da tecnologia como autoridade máxima, tomando como referência uma jornada histórica. A abordagem crítica pretende que o uso de um certo ponto de vista epistemológico e a despeito do fato de adquirir autoridade não cegue essas gerações a ponto de não colocar as possíveis desvantagens éticas e fazer com que seja chamada a atenção à promoção da dignidade humana em sua totalidade.

\section{METODOLOGÍA}

A metodologia desta dissertação é apresentada através da revisão da história da ciência e da filosofia em grandes etapas de forma comparativa em uma abordagem epistemológica e de ensaio.

\section{RESULTADOS}


O desenvolvimento humano é um tema fascinante, possiblitando um grande número de análises, desde a evolução material até à sua dimensão divina.

Há muitas linhas de estudo do desenvolvimento humano, mas nenhuma delas está na expectativa do resultado final, porque o resultado tem de ser um animale rationale, loquens, erectum et bimanun. Conhecemos o futuro do passado, o futuro de milhões de anos de desenvolvimento, nós!

Então, qualquer análise deste tipo não produz grandes resultados, apenas confirmando aquilo que é do nosso conhecimento. A teoria antrópica está presente! Somos assim porque somos assim! Mais do que uma viagem rumo a um destino, estudar o desenvolvimento humano é uma viagem à nossa ancestralidade. É uma viagem para o passado com todos os perigos próprios de tal tarefa.

A nossa viagem vai ser simbólica, construída através de uma metáfora, a metáfora das maçãs.

A maçã é um fruto muito vulgar, existindo em praticamente todos os continentes. Mas a maçã também é um símbolo conhecido em várias culturas. Há referências a este fruto na mitologia alemã, escandinava, grega e, como é sabido, na tradição cristã.

Também a ciência tem a sua maçã, como é simbolicamente apontado para Newton. Todos já tinham visto maçãs a cair, mas Newton foi o primeiro a perguntar porquê. Newton concretizou o aristotélico espanto.

Finalmente, as novas tecnologias também adoptaram como símbolo a maçã. A Apple tem como produto o famoso computador Macintosh, que nada mais é do que o nome de uma variedade de maçãs.

Coincidências? Talvez não.

Analisemos, então, o desenvolvimento humano através das maçãs.

\subsection{Primeira maçã: origem do conhecimento. $O$ bem e o mal}

A primeira maçã é óbvia. Trata-se da maçã de Adão e Eva.

É difícil entrar no universo cultural do Antigo Testamento. Há textos escritos mais de mil anos antes do nascimento de Cristo. Muitos desses textos foram narrados durante centenas de anos antes de serem fixados pela palavra escrita. A Bíblia nasceu para conservar a memória do povo, para não esquecer o passado. A escrita é um poderoso instrumento da memória humana.

O tempo antigo não é um tempo unitário, nem o Antigo Testamento é a história de um povo. É a história de vários povos e de muitos lugares, escrita em diversas línguas, durante um longo período de tempo e por muitos autores. A Bíblia não foi escrita como um manual ou uma novela. É um Livro complexo, impossível de ser compreendido através de uma leitura simples, pelo que a primeira maçã deverá ser entendida como uma interpretação pessoal do mito adâmico. 
A própria literatura de ficção refere o mito de Adão e Eva no sentido habitual atribuído ao valor da maçã. Este fruto é proibido. Foi a serpente que tentou o ser humano, sendo por isso uma transgressão.

Transgressão não é o mesmo que queda ou pecado. Significa "passar além do que estava permitido no processo de criação em curso". Adão e Eva não têm ainda o conhecimento. Não conhecem o bem ou o mal. Esse conhecimento é dado pelo fruto proibido, que na tradição popular é uma maça. Comer a maçã é o acto de conhecer. A maçã é o conhecimento. Concretiza-se no acto de "comer".

Assim, a simbólica maçã significa uma ruptura com o acto divino da criação. A maçã possibilitou adquirir o conhecimento, a civilização e a aquisição da condição de sofredor, mortal e trabalhador. Na perspectiva kantiana, podemos afirmar que maçã é o símbolo do primeiro dia após a criação divina. É metáfora da cultura no seu esplendor.

A primeira maçã invoca a origem do conhecimento. Para Aristóteles, reconhecimento é a passagem da ignorância para o conhecimento, uma transformação também de natureza ética. O conhecimento do bem e do mal é a consequência desta primeira maçã, começando então o verdadeiro desenvolvimento humano. Sófocles disse que a coisa mais prodigiosa no universo é o homem. Agora podemos afirmar que a realidade mais prodigiosa que nos dá o universo é o conhecimento.

O mito da caverna, de Platão, também nos fala da transgressão que é o conhecimento. Sócrates, provavelmente a figura imortalizada pelo referido mito, foi condenado porque dava conhecimento aos jovens.

Por outro lado, mais na perspectiva comum, a maçã permitiu que o ser humano ficasse também a conhecer a origem da vida.

\subsection{Segunda maçã: o conhecimento das leis do Universo. O racionalismo}

Para muitos autores, Newton é considerado o nome maior da ciência. O seu livro Principia é para Stephen Hawking "o mais importante trabalho na história da ciência e o fundamento científico da moderna visão de mundo" (p. 740). E tudo, simbolicamente, começou com uma maçã. Provavelmente a verdadeira maçã de Newton foi a $3^{\text {a }}$ lei de Kepler estabelecida 60 anos antes.

Qual metáfora, Newton refere que foi a queda de uma maçã que o despertou para o estudo da gravidade, que levou à escrita da Philosophiae Naturalis Principia Mathematica. Ao que parece, este nome contrastou com a Principia Philosophiae de René Descartes.

Através dos tempos, a filosofia assumiu-se como o conhecimento mais importante para o desenvolvimento da sociedade. O contributo da Antiga Grécia para a cultura ocidental é indiscutível. O ser humano foi profundamente pensado, e autores como Platão e Aristóteles continuam como referências fundamentais para o seu estudo. A 
filosofia antiga só é antiga porque foi pensada numa outra época. Continua actual em muitos dos seus temas centrais.

O conhecimento científico, aqui entendido de forma mais redutora, não teve o mesmo desenvolvimento da filosofia ou da religião. Não poderia ter! Antes de ser cientista o homem foi religiosus. Foi em torno da filosofia e da religião que uma concepção de mundo foi criada. A nova ciência não tinha lugar nessa visão do cosmos. Nada poderia colocar em causa a cosmovisão que criava uma harmonia existencial. Qualquer novo dado significava uma destruição nessa harmonia, provocando o fim de um sistema que funcionava.

Quando Copérnico propõe um novo esquema cósmico, uma tradição de 1500 anos foi desafiada.

O modelo desenvolvido por Copérnico era puramente mental, não havendo ainda lugar ao método experimental. Foi um homem do seu tempo, mas que abriu as portas ao pensamento do futuro.

O universo começou a ser visto como um sistema com regras, que levou mais tarde Newton a afirmar que o universo funciona sob princípios matemáticos.

Em rigor, o primeiro cientista tal como agora entendemos ciência, foi Galileu Galilei. Para Einstein, ele foi o pai da física moderna, e pai da ciência moderna.

Galileu Galileu, com a sua famosa frase Eppur si muove, também transgride. Põe em causa o conhecimento milenar sobre o universo e a própria Igreja.

Newton inaugurou um novo tempo, o tempo do progresso sem limites. Ao ver o infinito e ao entender as leis do universo, Newton cria na prática a ideia do ilimitado. Aristóteles via o universo sem princípio e sem fim, mas esta ideia só foi verdadeiramente assumida muito mais tarde.

Com Newton a física é colocada em causa! A vida é questionada, mas o homem continua a ser o mesmo! É a matemática que valida o infinito porque ela mesmo parece não ter limites. Até as ciências sociais e humanas se converteram à teologia da matemática! A estatística estabelece o que é regular e irregular, o normal e o anormal. O bem e o mal passam para a esfera da matemática/estatística, abandonando o seu carácter humano.

Também a maçã de Newton se constitui numa trangressão. Possiblita que o ser humano pense que pode chegar à omnisciência, ao conhecimento de tudo. Não basta conhecer, como é invocado pela primeira maçã! Temos de conhecer tudo! 0 infinito e o fractal unem-se no mesmo lugar! A física aproximou-se da metafísica e as novas perguntas da física ficam a aguardar as respostas da metafísica. A pergunta "o que havia antes do big-bang" é incómoda para muitos físicos, tal como foi incómoda a pergunta feita a Santo Agostinho "o que fazia Deus antes da criação?" ao que ele respondeu "não sei". Esta resposta humilde não serve para o actual cientista. Tem de saber e diz que vai saber. É o caminho triunfal da ciência que um dia tudo saberá!

A ideia do Criador parece não ter lugar na física ou na biologia contemporâneas, mas provavelmente Joseph Ratzinger tem razão quando afirma que o ser humano 
não pode ser apenas o produto de erros casuais como é sugerido por uma determinada corrente de pensamento encimada por Jacques Monod.

Esta segunda transgressão coloca ao homem problemas éticos fundamentais. Wittgenstein não vê na ciência a capacidade de resolver problema éticos. Mais ainda, a ciência, nas palavras de Edgar Morin, coloca ao ser humano novos problemas, não dando pistas para os resolver, como pode ser documentado com a clonagem e outras intervenções na vida, ou seja, com a terceira maçã.

As teorias de Copérnico, terreno primordial onde cresceu a macieira cujo fruto caiu na cabeça de Newton, poderiam levar as pessoas a crer que eram apenas partes de uma ordem natural, e não senhores da Natureza, o centro em torno da qual a Natureza estava ordenada. A importância desta transgressão não é menor que a maçã do Paraíso. É uma ruptura com a ideia fascinante: o homem não está no centro do Universo! Que transgressão!

\subsection{Terceira maçã. O conhecimento da criação de vida. A Caixa de Pandora}

O mundo actual está marcado pelo símbolo de uma empresa de tecnologia, a Apple. A biotecnologia, a engenharia genética, a terapia genética, a manipulação genética ou qualquer outra área de interface científica bem recente, permitiram que o ser humano tivesse acesso a dimensões da vida até aqui interditas. A própria criação deixou de ser algo para além da compreensão humana para se transformar num acto que pode ser mobilizado pela nossa vontade. Aquilo que apenas há alguns anos faria parte da ficção científica é hoje realidade. A clonagem, a replicação de células em laboratório e outras técnicas afins, fazem parte do nosso vocabulário diário, banalizando o acto mais transcendente, que é a própria criação da vida. Se antes criar era um desígnio divino e corrigir uma capacidade humana, hoje parece que o homem também quer assumir o papel de criador de vida.

Dalai-Lama, independentemente de qualquer outro juízo que possamos fazer em relação à sua doutrina religiosa, é muito feliz quando afirma que se o cientista verificar que a investigação em que está envolvido é susceptível de prejudicar os outros, devido ao sentimento de responsabilidade, deverá desistir dela. E por esta razão que o juízo ético consubstanciado na questão "até onde é que podemos ir" é de extrema complexidade neste nosso mundo onde os avanços técnicos parecem resolver todos os sonhos mais ousados, convidando-nos a cometer todos os devaneios, num genuíno eros científico que nos poderá levar à incapacidade de domínio dos próprios produtos do génio humano, abrindo de par em par a Caixa de Pandora da nossa existência. Por exemplo, a biotecnologia aplicada ao desporto poderá ser uma das chaves para abrir essa mítica caixa, com todos os riscos inerentes a tal tomada de decisão.

Mais do que viver, o homem existe. Não se limita à sua dimensão física e biológica, construindo um novo mundo, um mundo necessário à sua existencia

Nesta linha antropológica, encontramos Delfim Santos, filósofo e pedagogo português que viveu entre 1907 e 1966, ao adiantar que o homem é o único ser vivo que não encontra meio adequado, ao contrário do que acontece ao animal; mas que, 
criando um meio que não lhe é dado, a si próprio se cria estruturando novas formas artificiais de comunicação, de comunhão, de habitação, de alimentação e de correspondentes modos de actividade lúdica.

A técnica é um produto do espírito humano, sendo muito mais do que um instrumento, aproximando-se quase da essência humana. É uma importante dimensão da vida humana, tornando-se difícil separar desta a arte de produzir determinados artefactos ou modos de vida. O homo faber continua bem presente, apresentando-se a cada momento das nossas vidas.

É notório o aumento de importância da técnica nas nossas vidas, sendo esta evolução irreversível. Pensar um mundo desprovido das mais sofisticadas tecnologias parece ser uma impossibilidade. Todos os dias somos sujeitos da técnica no seu mais amplo espectro, seja nas deslocações para o emprego, a utilizar as tecnologias de informação e comunicação, seja em pequenos gestos do quotidiano, como é o caso da utilização de um simples aparelho de micro-ondas para aquecer ou confeccionar alimentos. Os gestos rotineiros estão de forma crescente impregnados de tecnologia. Sem a técnica a vida tornar-se-ia muito difícil. Ao que parece tudo se encontra invadido pela tecnologia, assumindo-se esta como um bem de primeira necessidade. Já o imortal Aristóteles aludia a estas necessidades, chamando a nossa atenção para a diferenciação entre instrumentos de produção e instrumentos de acção. A presença da técnica torna-se inegável nesta análise aristotélica.

Foi talvez balizado pela consciência da importância da tecnologia nas nossas vidas que levou Yves Michaud afirmar que l'homme est un animal technicien, tendo ousado, sem grandes dúvidas, afirmar que a humanidade e a técnica deverão ser apreendidas em conjunto, conferindo assim à técnica uma dimensão muito para além da instrumental, parecendo querer entrar com nitidez no campo de uma justificação de sinal ontológico. Por vezes, talvez com algum radicalismo conceptual, técnica e ser surgem de tal forma ligados que se torna difícil conceber uma sem a outra entidade. É por esta linha de raciocínio que Michel Serres adianta que vida e técnica tendem conjuntamente para a totipotência, que estamos perante um tema fascinante que tem de ser analisado sem preconceitos de ordem alguma.

A tecnologia mudou o nosso mundo possibilitando a emergência de um novo homem: um homem com uma outra concepção de espaço, que se pode anular com um simples clique numa tecla de computador; com uma outra percepção de tempo, que se reduz à sua expressão infinitesimal, que cria - palavra estranha - o nãolugar, onde estamos sem estar. A tecnologia desenvolveu outro homem, outra antropologia.

Admito algum fundamentalismo nesta visão transcendental da técnica, mas é inspirada por muitos autores que a vêem como uma promessa em prol da humanidade. Fernando Savater acredita que a técnica é a nossa empresa definitoriamente humana. Ainda este filósofo espanhol convida-nos para a reflexão, lembrando uma obra do sociólogo francês Michel Serres, intitulada Qu'est-ce que l'humain? Le temps humain: de l'evolution créatice au créateur d'évolution. Aquilo 
que a evolução criadora demora milhões de anos a produzir, o homem consegue (re)criar num breve lapso temporal.

Na óptica atrás apontada, um braço robótico é expressão da evolução num curto período de tempo induzido pelo homem quando comparado ao tempo necessário que levaria um ser vivo a "adquirir" tal braço de forma evolutiva. Esse braço poderá ser uma cópia da natureza - Aristóteles admitiu essa possibilidade na sua Física quando discutia a técnica - mas a velocidade com que o faz é extremamente elevada quando comparada com os ritmos normais da referida natureza.

Mas a tecnologia pode ser vista ainda através de uma outra forma. As ciências humanas podem tentar compreender a relação entre a técnica com a própria evolução das sociedades. O impacto das tecnologias da informação e de comunicação alterou por completo as sociedades, conferindo ao ser humano novas e amplas possibilidades de conhecimento, podendo assim modificar-se, modificando o meio. Estou certo que o mundo de hoje não é aquilo que foi perspectivado no passado mais recente. O desenvolvimento tecnológico repercute-se na aceleração da mudança das sociedades e do homem, o que leva a que questionemos inúmeros aspectos que até agora pareciam intocáveis. A educação é um desses aspectos. Nunca como agora o ideal da Paideia, isto é, a elevação do ser humano através da cultura e da educação, se coloca com tanta importância face a uma certa desumanização que a própria tecnologia pode impor ao homem.

Outro aspecto crítico nesta mudança provocada pelo desenvolvimento tecnológico é a noção de fronteira. Por esta entidade muitas pessoas morreram ao longo dos tempos. Os quilómetros demarcados pelas fronteiras entre os diversos países podem ser muito bem contabilizados em número de mortos. Houve países, e infelizmente ainda há, que construíram muralhas para se demarcarem. Noutros tempos o Império do Meio fê-lo. Mais tarde, quase no nosso tempo, a antiga República Democrática Alemã também o fez. Hoje, triste sinal dos tempos, os Estados Unidos e Israel querem afastar os seus vizinhos mexicanos e palestinianos através de novas muralhas. As lições da história não foram aprendidas.

No tempo presente a Internet, enquanto produto impressionante do espírito humano, não reconhece limites fronteiriços, inaugurando uma cultura virtual que a todos (bem, apenas alguns) atinge, ajudando a edificar um homem novo, um homo sapiens sapiens a que qualquer dia teremos de acrescentar algum sufixo designativo de ciência e de técnica, uma vez que estas condicionam fortemente o saber e a sapiência invocados pelo duplo sapiens.

Se o binómio ciência e técnica evolui, também estes conceitos não são estáticos ou absolutos, evoluindo em concomitância. Se a física moderna teve o condão de quebrar a ideia do determinismo absoluto e com isso provocar uma outra revolução científica, outra perturbação tem sido estimulada pelo reagrupamento de inúmeros ramos do saber, como muito bem nos alerta Edgar Morin. Embora não me assumindo como particular adepto das ciências da complexidade, não tanto por elas mas por algum uso indevido dessa expressão que pode legitimar a ausência de um verdadeiro sentido de responsabilidade, reconheço a sua capacidade integradora do 
homem no cosmos, isto é, a tentativa de compreender o homem na sua totalidade e não espartilhado por saberes herméticos.

Voltemos à nossa maçã. As maçãs de Eva e de Newton convocam duas transgressões. Esta nova maçã, a Apple, também comporta uma transgressão. Provavelmente será a mais importante porque entra no domínio da violação do acto de criar. Criar deixou de ser um acto divino para poder ser efectuado pelo homem sem nenhuma vigilância ética. Se Eva conheceu o bem e o mal e assim decidir o seu comportamento, agora o próprio mal pode ser transmitido para a vida. Com esta possibilidade de criar vida já com o fermento do mal, não mais se torna necessária a primeira maçã da nossa metáfora. O bem e o mal deixam de ser fruto da consciência humana para passarem a fazer parte do património genético humano. Que perigosa maçã é esta possibilitada por possíveis desvarios da Apple...

O ser humano começa a perder dignidade, tendo um preço como tem qualquer coisa desprovida de dignidade. Mais do que nunca, é fundamental recuperar o conceito de dignidade humana proposto por Kant. A dignidade deverá voltar a ocupar a centralidade da existência humana.

\section{CONCLUSIONES Y DISCUSIÓN}

6.

Três dos mais importantes acontecimentos do desenvolvimento humano têm como símbolo a maçã. Este fruto aparece simbolizando o conhecimento humano e com ele as transgressões efectuadas pelo homem:

1. A primeira maçã simboliza a origem do conhecimento.

2. A segunda maçã traduz a origem do conhecimento das leis do universo.

3. A terceira maçã indica a possibilidade do homem criar vida e vida humana ou, pelo menos, a manipular a sua criação.

A primeira maçã corresponde ao momento em que o homem decide não aceitar as limitações da sua existência. Passa a deter o conhecimento, não se limitando ao seu puro dado, perdendo a sua inocência primordial.

A segunda maçã representa a certeza matemática, postulando que a verdade é aquilo que pode ser confirmado pela experiência. A primeira maçã, o bem e o mal, não é traduzida por um algoritmo matemático. Bem e mal não são nada porque a matemática não os pode prever! Esta maçã revela as leis do universo, obviamente matemáticas, instaurando uma nova visão do homem, o racionalismo. O ser humano perde a sua centralidade no cosmos, passando a ser apenas mais um seu elemento.

A terceira maçã da nossa metáfora evidencia que a criação de vida já caiu no domínio humano, abandonando o seu carácter insondável, entrando no campo das realizações humanas. Parece que a vida, toda a vida, inclusive a humana, é um produto de laboratório, perdendo a sua dignidade, entrando no reino das coisas, e por tal tendo um preço.

São Tomás de Aquino, na sua Suma Teológica, discute se o ser humano no seu estado de inocência era imortal, concluindo que não. Não poderá a quarta maçã 
estabelecer a imortalidade humana, transportando o homem para um estado que nem a Criador concebeu? A busca da imortalidade é uma constante nos discursos da terceira maçã. Ainda não se concretizou, mas a macieira humana é muito produtiva...

Finalmente, o desenvolvimento humano pode ser comparado a uma cebola. Sim, agora nesta metáfora de frutos usamos a cebola que tem muitas pequenas camadas, mas que no fim formam um importante volume. Cada maçã significa uma camada no nosso desenvolvimento, mas o ser humano não é um ente acabado. A sua evolução continua, pelo que podemos perguntar: Qual será mesmo a quarta maçã? A imortalidade? Que nova transgressão significará esta maçã? Que limites serão ultrapassados? Fará sentido ainda falar de um ser criado à imagem do Criador?

A consciência histórica do ser humano possibilita ter presente dentro de si todo o passado da humanidade. Cada homem actual "come" as três maçãs. Somos homo sapiens sapiens, pelo que nos sabemos possuidores de conhecimento, do conhecimento simbolizado pelas três maçãs.

\section{$\underline{\text { Nota final }}$}

A ideia para esta conferência ocorreu em Múrcia. O texto foi escrito no Porto, em Manaus, em Luanda e foi concluído no quarto de um hospital. Por tal, é um texto viajado e sofrido...

\section{REFERENCIAS}

\section{Libros:}

Alfred Kröeber (1993), A natureza da cultura, defende, na linha de Kant, que cultura é um acrescento à natureza. Lisboa: Edições 70. Assim, esta maçã corresponde à cultura.

Armindo dos Santos Vaz (2011). O sentido último da vida projectado nas origens. Marco de Canavezes: Edições Carmelo.

Aristóteles, (edição de 2008) Poética. Lisboa: Fundação Calouste Gulbenkian. América

Edgar Morin (2005). O método VI. Ética. Mem-Martins: Publicações Europa-

Eduardo Roca (2013). A oficina dos livros proibidos. O conhecimento pode mudar o mundo. Barcarena: Marcador Presença.

Fernando Savater (2004). A coragem de escolher. «O núcleo essencial de tudo o que escrevi». Lisboa: Dom Quixote

Georges Steiner (2008). A ciência está perto dos limites? In A ciência terá limites? (org. Georges Steiner): Lisboa: Fundação Calouste Gulbenkian 
Jacques Monod (2002). O Acaso e a necessidade. Mem-Martins: Publicações Europa-América

John Gribbin (2005). História da ciência. De 1543 ao presente. Mem-Martins: Publicações Europa-América. Princípia

Joseph Ratzinger (2013). No princípio Deus criou o Céu e a Terra. Cascais:

Kant, Immanuel (2004). Fundamentação da metafísica dos costumes. Porto: Porto Editora [Edição original de 1785] Fontes

Luc Ferry (1999) intitulado A sabedoria dos modernos. São Paulo: Martins

Manuel Patrício e Luís Sebastião (2004). Conhecimento do mundo social e da vida. Passos para uma pedagogia da sageza. Lisboa: Universidade Aberta.

Marc Auge (2006). Não-lugares: introdução a uma antropologia da supermodernidade. Lisboa: 90 Graus.

Michel Serres (2004). Hominescência. Lisboa: Instituto Piaget

Platão. A República. Lisboa: Fundação Calouste Gulbenkian.

Santo Agostinho. Confissões. São Paulo: Martin Claret (Edição de 2002). data).

Sófocles. Antígona - Ájax - Rei Édipo. Lisboa: Editorial Verbo (edição sem

Stephen Hawking (2010). Aos ombros de gigantes. Alfragide: Texto Editores.

Werner Jaeger (2003). Paidéia. A formação do homem grego. São Paulo: Martins Fontes.

Artículos en revistas:

Delfim Santos (1965). A técnica como fundamento da cultura. In Obras completas -Do homem. Da cultura (tomo III). Lisboa: Fundação Calouste Gulbenkian (edição de 1987), p. 496.

Não é minha intenção desenvolver a perspectiva aristotélica aqui apresentada. Em Política está bem desenvolvida. Lisboa: Veja (edição de 1998), pp. 57-77.

Pierre Caspar (2001) L'accès au savoir: permanences et mutations. In Yves Michaud (dir.) Qu'est-ce que les technologies? (vol. 5). Paris: Éditions Odile Jacob, pp. 17-26.

São Tomás de Aquino: Suma Teológica (vol. Il, questão 97, artigo 1). São Paulo: Edições Loyola (ed. 2002) 
Rui Proença Garcia

Yves Michaud (2001). Introduction. In Yves Michaud (dir.). Qu'est-ce que les technologies (vol. 5). Paris: Éditions Odile Jacob, p. 7. 